\title{
When should we start renal-replacement therapy in critically ill patients with acute kidney injury: do we finally have the answer?
}

\author{
Sean M. Bagshaw ${ }^{1 *} \mathbb{D}$, Eric A. Hoste ${ }^{2}$ and Ron Wald ${ }^{3}$
}

\section{"To climb steep hills requires a slow pace at first."}

William Shakespeare

\section{Background}

A significant proportion of critically ill patients with severe AKI, particularly those who develop refractory complications [1], receive support with renal-replacement therapy (RRT) [2]. There has been a longstanding dilemma on when RRT should be started for patients with severe AKI, specifically among those without AKIrelated complications that could be addressed by RRT. Among patients with urgent or refractory complications, there is consensus for starting RRT. However, should RRT be started earlier in the course of AKI to pre-empt complications or judiciously delayed and started if and when complications arise? Furthermore, clinicians are challenged to select those patients who will have high probability of clinical benefit (restore metabolic/fluid homeostasis) and improved outcome (survival, recovery, quality of life) and to avoid RRT in patients who do not need it, will not benefit from it or who have greater probability of experiencing harm from it.

Several randomized trials have shown that an earlier strategy for starting RRT does not confer a survival advantage, can increase the risk of harm (dialysis

\footnotetext{
*Correspondence: bagshaw@ualberta.ca

${ }^{1}$ Department of Critical Care Medicine, Faculty of Medicine and Dentistry, University of Alberta and Alberta Health Services, 2-124E Clinical Science Building, 8440-112 Street NW, Edmonton, AB T6G2B7, Canada

Full list of author information is available at the end of the article
}

dependence [3], bacteremia [4]) and portend greater resource use compared with a "watch-and-wait" or delayed strategy [3-5]. These trials now support the broad notion that deferral of RRT, pending the development of urgent indications, should be adopted as the default strategy. The rationale for a "watch-and-wait" approach is to provide opportunity to observe for recovery and to avoid RRT in selected patients [3-5]. However, the variables that define "deferral" remain uncertain. Specifically, when confronted with patients who have severe and non-resolving AKI, for how long can deferral be considered safe and acceptable? This was addressed by the recent Artificial Kidney Initiation in Kidney Injury-2 (AKIKI-2) trial [6].

AKIKI-2 was a multi-centre trial comparing two strategies for delayed RRT initiation in 278 patients. Similar to AKIKI, patients fulfilled criteria for Stage 3 AKI and were receiving either mechanical ventilation and/or vasopressors. However, where AKIKI-2 differed is that eligibility specified a protracted AKI course, defined by oligo-anuria for $\geq 72 \mathrm{~h}$ and/or a serum urea $40-50 \mathrm{mmol} / \mathrm{L}$ (112$140 \mathrm{md} / \mathrm{dL}$ ). Upon fulfilling these criteria, patients were randomized to "delayed" RRT (aligned with the delayed strategy of AKIKI [4]) started within $12 \mathrm{~h}$ of randomization or "more-delayed" RRT, defined by deferring RRT until an urgent indication emerged or serum urea exceeded $50 \mathrm{mmol} / \mathrm{L}$ (140 md/dL). Oligo-anuria was not a trigger for RRT in the more-delayed strategy. The primary outcome was "days-alive and RRT-free" from randomization through 28 days, conditional on patients being alive and RRT free for 3-consecutive days. original author(s) and the source, provide a link to the Creative Commons licence, and indicate if changes were made. The images or other third party material in this article are included in the article's Creative Commons licence, unless indicated otherwise in a credit line to the material. If material is not included in the article's Creative Commons licence and your intended use is not permitted by statutory regulation or exceeds the permitted use, you will need to obtain permission directly from the copyright holder. To view a copy of this licence, visit http://creativecommons.org/licenses/by/4.0/. The Creative Commons Public Domain Dedication waiver (http://creativeco mmons.org/publicdomain/zero/1.0/) applies to the data made available in this article, unless otherwise stated in a credit line to the data. 


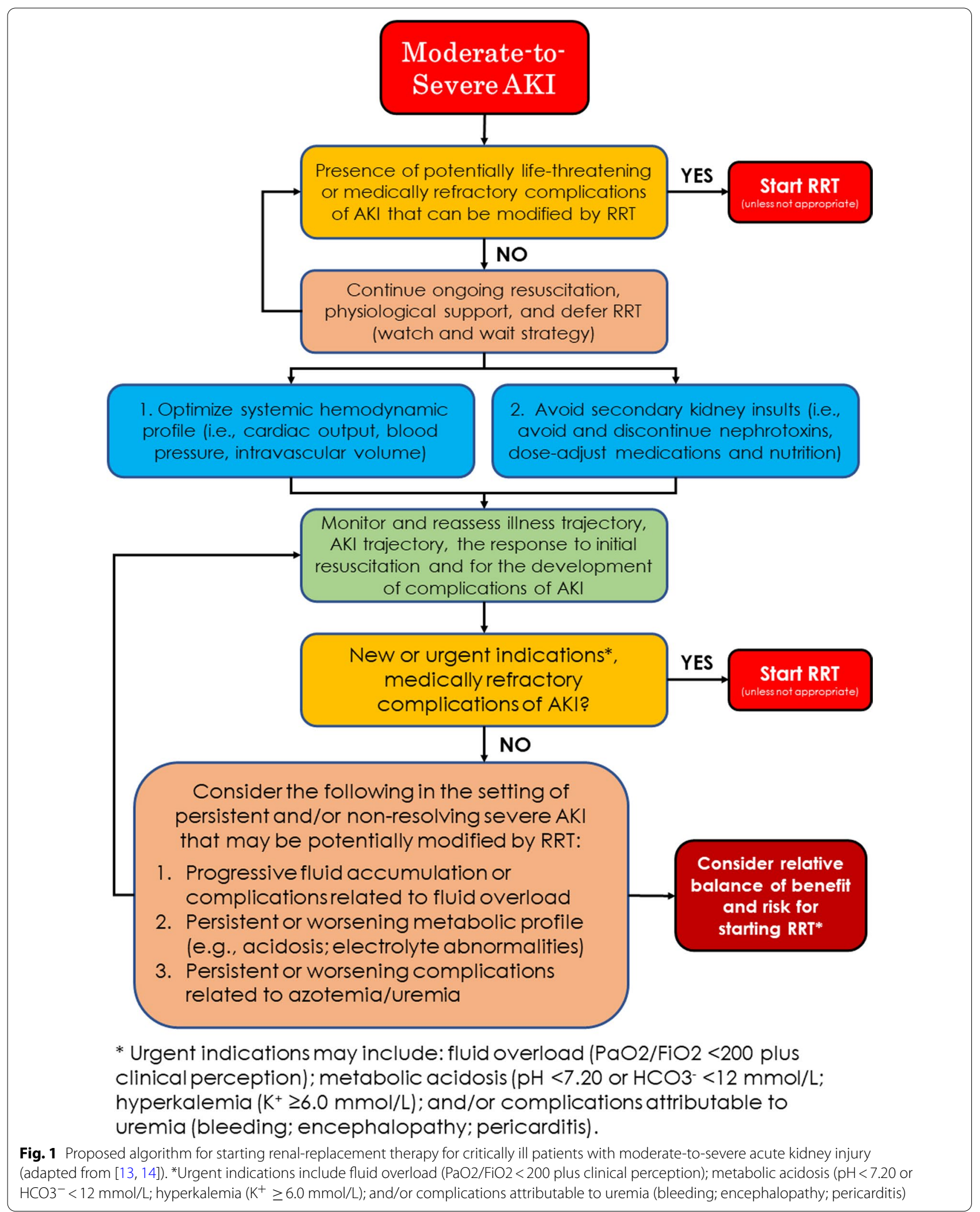


RRT-free days did not differ between the strategies. There were also no differences in secondary endpoints, including ventilator-free days, ICU stay or kidney recovery. In a pre-specified analysis, allocation to the more-delayed strategy was found to increase the hazard of death (adjusted-HR 1.65) compared with the delayed strategy.

Inherent in the AKIKI-2 design, it was hypothesized that the more-delayed strategy would increase in RRT-free days. It is therefore notable that RRT-free days were not greater with the more-delayed strategy, despite fewer patients receiving RRT and when initiated, occurring $\sim 2$ days later, when compared with the delayed strategy. As such, the likely driver of the primary outcome was higher mortality with the moredelayed strategy. This could have plausibly been driven by several factors, such as the effects of prolonged untreated AKI, exaggerated non-renal organ dysfunction (e.g., delirium [7]) and modified recovery from critical illness [8]. The protocol embedded precautions to prevent intra-dialytic hypotension and dialysisdisequilibrium syndrome, but these events were not reported. Finally, small and unblinded trials would be susceptible to biased co-interventions, such as withdrawal of life-sustaining treatments.

AKIKI-2 is applicable to a small proportion of patients with AKI. Of the 5,336 patients screened, only 767 (14.4\%) fulfilled the initial eligibility. Of the 4,466 initially excluded, $42.9 \%$ failed to achieve Stage 3 AKI and many were excluded for urgent indications (13.5\%) or prior RRT (6.8\%). Moreover, of those with Stage 3 AKI who were excluded, 127 (26.0\%) developed an urgent indication after a median (IQR) of 35 (17-68) hours and received $\mathrm{RRT}$, while the remainder did not fulfil randomization criteria.

Similar to AKIKI, AKIKI-2 again suggests that serum urea as a primary trigger is not ideal for identification of the optimal timing of RRT, regardless of the thresholds evaluated [9]. First, serum urea was not useful for identifying patients with an increased mortality risk [10]. We currently lack robust data on serum urea thresholds that constitute toxicity. Rather than a specific threshold, the duration of elevated serum urea may be a better surrogate for the development of uremic-related complications. Second, serum urea is influenced by a range of factors other than impaired excretion, including excess protein catabolism, corticosteroid administration, exogenous protein or gastrointestinal bleeding and volume contraction. Finally, the thresholds of serum urea did not discriminate patients with urgent indications for RRT: $16.6 \%$ of Stage 3 AKI patients had urgent indications developed prior to the delayed criteria being fulfilled, and $33 \%$ of patients in the more-delayed strategy developed urgent indications prior to the protocolized serum urea threshold ( $>50 \mathrm{mmol} / \mathrm{L}$ ) was fulfilled.

AKIKI-2 highlights the need for robust and validated tools that discriminate between patients with AKI who are most likely to need and benefit from starting RRT from those in whom it can or should be avoided. Such tools include clinical prediction by machine learning [11], predictive enrichment with AKI sub-phenotypes, use of the furosemide stress test and emerging biomarkers of persistent severe AKI [12].

\section{Conclusions}

Recent evidence has shown that pre-emptive or earlier RRT in patients with severe AKI and no urgent indications does not confer clinical benefit. By default, this would imply that a more judicious "watch and wait" strategy is acceptable. The findings of AKIKI-2 reinforce that there are limitations and harm to protracted delays in RRT initiation in patients with severe and persistent AKI [6]. Clinicians are bound to remain challenged by a lack of clarity on the optional circumstances to initiate RRT until additional evidence emerges. In the meantime, such uncertainty should not negate the importance of sound patient-centred practice grounded in the available evidence (Fig. 1). Clinicians should integrate an individual patient's evolving critically illness, their dynamic response to interventions, the trajectory of AKI and likelihood for recovery, and importantly, patient and family preferences for care.

\section{Acknowledgements}

SMB is supported by a Canada Research Chair in Critical Care Nephrology.

Authors' contributions

All authors wrote, revised and approved the final manuscript.

Funding

Not applicable.

\section{Declarations}

Availability of supporting data

Not applicable.

Ethical approval and consent to participate

Not applicable.

Consent for publication

Not applicable.

\section{Competing interests}

$\mathrm{SMB}$ discloses consulting fees and grant support from Baxter and consulting fees from CNA Diagnostics. EAH discloses fees for speaking from Sopachem and a travel grant from AM Pharma. RW discloses grant support and speaking fees from Baxter.

\section{Author details}

${ }^{1}$ Department of Critical Care Medicine, Faculty of Medicine and Dentistry, University of Alberta and Alberta Health Services, 2-124E Clinical Science Building, 8440-112 Street NW, Edmonton, AB T6G2B7, Canada. ${ }^{2}$ Intensive 
Care Unit, Ghent University Hospital, Ghent, Belgium. ${ }^{3}$ Division of Nephrology, St. Michael's Hospital and the University of Toronto and the Li Ka Shing Knowledge Institute of St. Michael's Hospital, 30 Bond Street, Toronto, ON M5B 1W8, Canada.

Received: 5 May 2021 Accepted: 7 May 2021

Published online: 26 May 2021

\section{References}

1. Liborio AB, Leite TT, Neves FM, Teles F, Bezerra CT. AKI complications in critically ill patients: association with mortality rates and RRT. Clin J Am Soc Nephrol. 2015;10(1):21-8.

2. Vincent JL, Marshall JC, Namendys-Silva SA, Francois B, Martin-Loeches I, Lipman J, Reinhart K, Antonelli M, Pickkers P, Njimi H, et al. Assessment of the worldwide burden of critical illness: the intensive care over nations (ICON) audit. Lancet Respir Med. 2014;2(5):380-6.

3. STARRT-AKI Investigators, Canadian Critical Care Trials Group tA, New Zealand Intensive Care Society Clinical Trials Group tUKCCRGtCNTN, the Irish Critical Care Trials G, Bagshaw SM, Wald R, Adhikari NKJ, Bellomo R, da Costa BR, Dreyfuss D, et al. Timing of initiation of renal-replacement therapy in acute kidney injury. N Engl J Med. 2020;383(3):240-51.

4. Gaudry S, Hajage D, Schortgen F, Martin-Lefevre L, Pons B, Boulet E, Boyer A, Chevrel G, Lerolle N, Carpentier D, et al. Initiation strategies for renal-replacement therapy in the intensive care unit. N Engl J Med. 2016;375:122-33

5. Barbar SD, Clere-Jehl R, Bourredjem A, Hernu R, Montini F, Bruyere R, Lebert C, Bohe J, Badie J, Eraldi JP, et al. Timing of renal-replacement therapy in patients with acute kidney injury and sepsis. N Engl J Med. 2018:379(15):1431-42.

6. Gaudry S, Hajage D, Martin-Lefevre L, Lebbah S, Louis G, Moschietto S, Titeca-Beauport D, Combe B, Pons B, de Prost N, et al. Comparison of two delayed strategies for renal replacement therapy initiation for severe acute kidney injury (AKIKI 2): a multicentre, open-label, randomised, controlled trial. Lancet. 2021;397(10281):1293-300.
7. Siew ED, Fissell WH, Tripp CM, Blume JD, Wilson MD, Clark AJ, Vincz AJ, Ely EW, Pandharipande PP, Girard TD. Acute kidney injury as a risk factor for delirium and coma during critical illness. Am J Respir Crit Care Med. 2017;195(12):1597-607.

8. Abdel-Kader K, Girard TD, Brummel NE, Saunders CT, Blume JD, Clark AJ, Vincz AJ, Ely EW, Jackson JC, Bell SP, et al. Acute kidney injury and subsequent frailty status in survivors of critical illness: a secondary analysis. Crit Care Med. 2018;46(5):e380-8.

9. Mackenzie J, Chacko B. An isolated elevation in blood urea level is not "uraemia" and not an indication for renal replacement therapy in the ICU. Crit Care. 2017;21(1):275.

10. De Corte W, Vanholder R, Dhondt AW, De Waele JJ, Decruyenaere J, Danneels C, Claus S, Hoste EA. Serum urea concentration is probably not related to outcome in ICU patients with AKI and renal replacement therapy. Nephrol Dial Transplant. 2011;26(10):3211-8.

11. Churpek MM, Carey KA, Edelson DP, Singh T, Astor BC, Gilbert ER, Winslow C, Shah N, Afshar M, Koyner JL. Internal and external validation of a machine learning risk score for acute kidney injury. JAMA Netw Open. 2020;3(8):e2012892.

12. Hoste E, Bihorac A, Al-Khafaji A, Ortega LM, Ostermann M, Haase M, Zacharowski K, Wunderink R, Heung M, Lissauer M, et al. Identification and validation of biomarkers of persistent acute kidney injury: the RUBY study. Intensive Care Med. 2020;46(5):943-53.

13. Bagshaw SM, Uchino S, Bellomo R, Morimatsu H, Morgera S, Schetz M, Tan I, Bouman C, Macedo E, Gibney N, et al. Timing of renal replacement therapy and clinical outcomes in critically ill patients with severe acute kidney injury. J Crit Care. 2009;24(1):129-40.

14. Ostermann M, Wald R, Bagshaw SM. Timing of renal replacement therapy in acute kidney injury. Contrib Nephrol. 2016;187:106-20.

\section{Publisher's Note}

Springer Nature remains neutral with regard to jurisdictional claims in published maps and institutional affiliations.
Ready to submit your research? Choose BMC and benefit from:

- fast, convenient online submission

- thorough peer review by experienced researchers in your field

- rapid publication on acceptance

- support for research data, including large and complex data types

- gold Open Access which fosters wider collaboration and increased citations

- maximum visibility for your research: over $100 \mathrm{M}$ website views per year

At BMC, research is always in progress.

Learn more biomedcentral.com/submissions 